\title{
Improvement of Dispersion and Color Effect of Organic Pigments in Polymeric Films via Microencapsulation by the Miniemulsion Technique
}

\author{
Dongming Qi, ${ }^{1}$ Zhijie Chen, ${ }^{1}$ Lei Yang, ${ }^{1}$ Zhihai Cao, ${ }^{2}$ and Minghua Wu ${ }^{1}$ \\ ${ }^{1}$ Key Laboratory of Advanced Textile Materials and Manufacturing Technology of China Educational Ministry, \\ Zhejiang Sci-Tech University, Hangzhou 310018, China \\ ${ }^{2}$ College of Materials, Chemistry and Chemical Engineering, Hangzhou Normal University, Hangzhou 310036, China
}

Correspondence should be addressed to Dongming Qi; dongmingqi@zstu.edu.cn

Received 1 December 2012; Revised 10 May 2013; Accepted 13 May 2013

Academic Editor: Abbas Milani

Copyright (C) 2013 Dongming Qi et al. This is an open access article distributed under the Creative Commons Attribution License, which permits unrestricted use, distribution, and reproduction in any medium, provided the original work is properly cited.

\begin{abstract}
Three primary pigment/poly $(n$-butyl acrylate-co-styrene) $(\mathrm{P}(\mathrm{BA}+\mathrm{St}))$ nanocomposites were prepared via encapsulation of the corresponding organic pigments via the miniemulsion technique. The resulting latexes of the $\mathrm{P}(\mathrm{BA}+\mathrm{St}) /$ pigment nanocomposites were filmed in a PTFE mould or printed onto cotton fabric. The morphology of the $\mathrm{P}(\mathrm{BA}+\mathrm{St}) /$ pigment nanocomposites and the dispersion of pigment particles in the latex film and on the printed fabric surface, as well as the adhesion between pigment and adhesive film, were evaluated by transmission electron microscopy (TEM), field emission scanning electron microscopy (FESEM), 3D digital microscope system (3D-POM), and printing results tests. Attributing to the preprotection of adhesive polymer shell, the self-adhesive $\mathrm{P}(\mathrm{BA}+\mathrm{St})$ /pigment nanocomposites were homogeneously and firmly dispersed both in the thin latex film and in the adhesive layer on the fiber surface. As a result, the color strength, color fastness, and handle of the fabrics printed by the $\mathrm{P}(\mathrm{BA}+\mathrm{St}) /$ pigment nanocomposites latex were significantly improved, compared to the fabrics printed by the conventional pigment blended latex.
\end{abstract}

\section{Introduction}

Organic pigments have been widely used in coating, paint, and printing industries due to their numerous advantages in photosensitivity, color strength, transparency, and so forth. However, organic pigments are difficult to be wetted and dispersed in water or in a polymeric film on a target matrix surface [1]. Thus, a large amount of dispersers and adhesives is normally required to promote the dispersion of organic pigments in films. However, the addition of these additives often leads to poor printing qualities, such as low color fastness, weak color strength, and poor color uniformity. Encapsulation of organic pigment particles by an adhesive polymeric shell before application was regarded as one of the most effective ways to overcome these problems [2].

In past decades, a rapid development of heterogeneous polymerization technology for encapsulating pigments has emerged, and a series of nanocomposites and microcomposites have been successfully prepared via emulsion polymerization [3, 4], miniemulsion polymerization [5-7], suspension polymerization $[8,9]$, or microsuspension polymerization $[10,11]$, respectively. However, in these mentioned reports, the pigment particles generally should be specially designed and modified. In addition, the shell materials were always rigid, such as polystyrene (PSt) in most cases. All these severely limit their extensive applications in coating, paint, and printing industries.

In our previous study, three primary color organic pigment cakes had been effectively encapsulated by $\operatorname{poly}(n$ butyl acrylate-co-styrene $)(\mathrm{P}(\mathrm{BA}+\mathrm{St}))$, which has a low glass transition temperature, via in situ microsuspension polymerization technology. A series of polymer/organic pigment microcomposites with a guava-like structure and different colors were prepared [11]. In this paper, polymer/pigment 
nanocomposites with smaller particle sizes $[6,12]$ and better self-adhesion were prepared via the miniemulsion technique. And they were applied to the film formation and the pigment printing of cotton fabrics. Thanks to the encapsulation of pigments in an adhesive shell, the cotton fabrics printed by the latexes of the polymer/pigment nanocomposites reveal a much better color strength, a better color fastness, and a better handle in comparison to those printed by pigment blended latexes.

\section{Experimental}

2.1. Materials. Three primary color organic pigment cakes, copper phthalocyanine blue 15 (PB), benzidine yellow G (PY), and Seikafast red 8040 (PR) were kindly supplied by Zhejiang Lily Group Co., Ltd. Monomers $n$-butyl acrylate (BA) and styrene (St) supplied by Shanghai Gaoqiao Chemical Co., Ltd. were distilled under reduced pressure and kept refrigerated until use. Initiator 2,2' -azobisisobutyronitrile (AIBN) was obtained from Aldrich Chemical Co., Ltd. Emulsifier sodium dodecyl sulfate (SDS) and costabilizer hexadecane (HD) with analytical purity were purchased from Shanghai No. 2 Chemistry Reagent Co., Ltd. Cotton fabric was kindly supplied by Zhejiang Huatai Silk Co., Ltd. Thickener PTF was purchased from UK Allied Colloids.

\subsection{Preparation of Pigment Microcapsules via Miniemulsion} Polymerization. A certain amount of organic pigment cake, AIBN, HD, and monomer was gradually added into the aqueous solution of SDS under a stirring state. The mixture was then ultrasonicated for $60 \mathrm{~s}$ (output power: $400 \mathrm{~W}$, work time: $10 \mathrm{~s}$, and pause time: $5 \mathrm{~s}$ ) under cooling with ice water to get a stable miniemulsion. The obtained miniemulsion was added into a $200 \mathrm{~mL}$ jacket glass reactor fitted with a condenser, a $\mathrm{N}_{2}$ inlet, a thermometer, and a paddletype agitator. And the miniemulsion polymerization was conducted at $70^{\circ} \mathrm{C}$ for $5 \mathrm{~h}$ under a $\mathrm{N}_{2}$ atmosphere and a shear field $\left(120 \mathrm{r} \cdot \mathrm{min}^{-1}\right)$ to obtain a series of polymer/pigment nanocomposites (defined as $\mathrm{P}(\mathrm{BA}+\mathrm{St}) / \mathrm{PY}, \mathrm{P}(\mathrm{BA}+\mathrm{St}) / \mathrm{PB}$, and $\mathrm{P}(\mathrm{BA}+\mathrm{St}) / \mathrm{PR}$, resp.). The schematic representation of the typical polymerization process was shown in Figure 1. And a typical recipe for the preparation of pigment microcapsules was as follows: pigment cake: $1.50 \mathrm{~g}$; BA: $6.00 \mathrm{~g}$; St: $4.00 \mathrm{~g}$; HD: $0.30 \mathrm{~g}$; SDS: $0.30 \mathrm{~g}$; AIBN: $0.50 \mathrm{~g} ; \mathrm{H}_{2} \mathrm{O}: 88.0 \mathrm{~g}$.

To compare, the mixture of organic pigments, $\operatorname{poly}(n-$ butyl acrylate-co-styrene) particles, and SDS aqueous solution was ultrasonicated for $60 \mathrm{~s}$ (output power: $400 \mathrm{~W}$, work time: $10 \mathrm{~s}$, and pause time: $5 \mathrm{~s}$ ) under cooling with ice water, to obtain three pigment blended latexes (defined as $\mathrm{P}(\mathrm{BA}+\mathrm{St})$ $\mathrm{PY}, \mathrm{P}(\mathrm{BA}+\mathrm{St})-\mathrm{PB}$, and $\mathrm{P}(\mathrm{BA}+\mathrm{St})-\mathrm{PR}$, resp.). This blending process imitates the preparation process of conventional pigment printing paste, and its recipe is similar to that of the latex of polymer/pigment nanocomposites. It should be pointed out that many macroaggregates were formed if the pigment blended latexes were further stirred at $70^{\circ} \mathrm{C}$ for $5 \mathrm{~h}$ after sonication. This could be reasonably attributing to the weak dispersing ability of agitation and strong adhesion ability of $\mathrm{P}(\mathrm{BA}+\mathrm{St})$ at $70^{\circ} \mathrm{C}$. Thus, the color quality of the resulting film was poor. Therefore, the pigment blended latexes were prepared without the stirring process.

To accurately observe the morphology of latex particles, rigid monomer styrene was used alone. And the latex of PSt/PB nanocomposite and the blended PSt-PB latex were prepared by miniemulsion polymerization and emulsion blending, respectively.

2.3. Preparation of Pigment Latex Film. The latex of polymer/pigment nanocomposites and the blended latex were added into a PTFE mould and dried at temperature $35^{\circ} \mathrm{C}$ and humidity of $65 \%$ for $24 \mathrm{~h}$. A series of thin films with a thickness of $50 \mu \mathrm{m}$ were obtained after annealing at $70^{\circ} \mathrm{C}$ for $1 \mathrm{~h}$.

2.4. Pigment Printing of Cotton Fabric. A certain amount of thickener PTF was added into the latex of polymer/pigment nanocomposites and the blended latex under a stirring state, to obtain the printing paste. The cotton fabrics were handscraped along the radial direction of fabric. The printed fabrics were baked at $80^{\circ} \mathrm{C}$ for $5 \mathrm{~min}$ and then at $115^{\circ} \mathrm{C}$ for $3 \mathrm{~min}$.

2.5. Characterization and Measurements. The morphology of the polymer/pigment nanocomposites and the particles in the blended latex was observed by a JEM-1230 transmission electron microscope (TEM, JEOL). The surface morphology of the latex film was observed by an ULTRA 55 field emission scanning electron microscope (FESEM, Zeiss). The dispersion of pigment in latex film was evaluated by a KH-7700 3D digital microscope system (3D-POM, Hirox). The color strength $(K / S$ value) of pigment printed cotton fabric was measured by an SF600X spectrophotometer color measurement (Datacolour). The stiffness of pigment printed cotton fabric was measured by an LYB-05 automatic fabric stiffness tester. The wet and dry rubbing fastnesses of the printed cotton fabric were standard tested by GB/T3920-1997 and GB251-1995.

\section{Results and Discussion}

3.1. Morphology of Pigment Microcapsules. The polymer/pigment nanocomposites were prepared via the copolymerization of BA and St in the nanodroplets containing pigment particles. The colloidal stability in the process of polymerization was well controlled. The digital photos of the products $\mathrm{P}(\mathrm{BA}+\mathrm{St}) / \mathrm{PY}, \mathrm{P}(\mathrm{BA}+\mathrm{St}) / \mathrm{PB}$ and $\mathrm{P}(\mathrm{BA}+\mathrm{St}) / \mathrm{PR}$ are shown in Figure 2(a). These latexes of polymer/pigment nanocomposites were homogenous and colorful. No sedimentation or flocculation phenomenon was observed after storing for six months, indicating good storage stability. Furthermore, it could be obviously seen that the color strength of the nanocomposite latexes is far stronger than that of the corresponding blended latexes in Figure 2(a). This could be regarded as a sign revealing the different dispersions of pigments in these two latexes.

The dispersion of pigment particles in the nanocomposite latexes and the blended latexes was further evaluated by TEM, and the typical TEM micrographs were shown in Figure 3. 


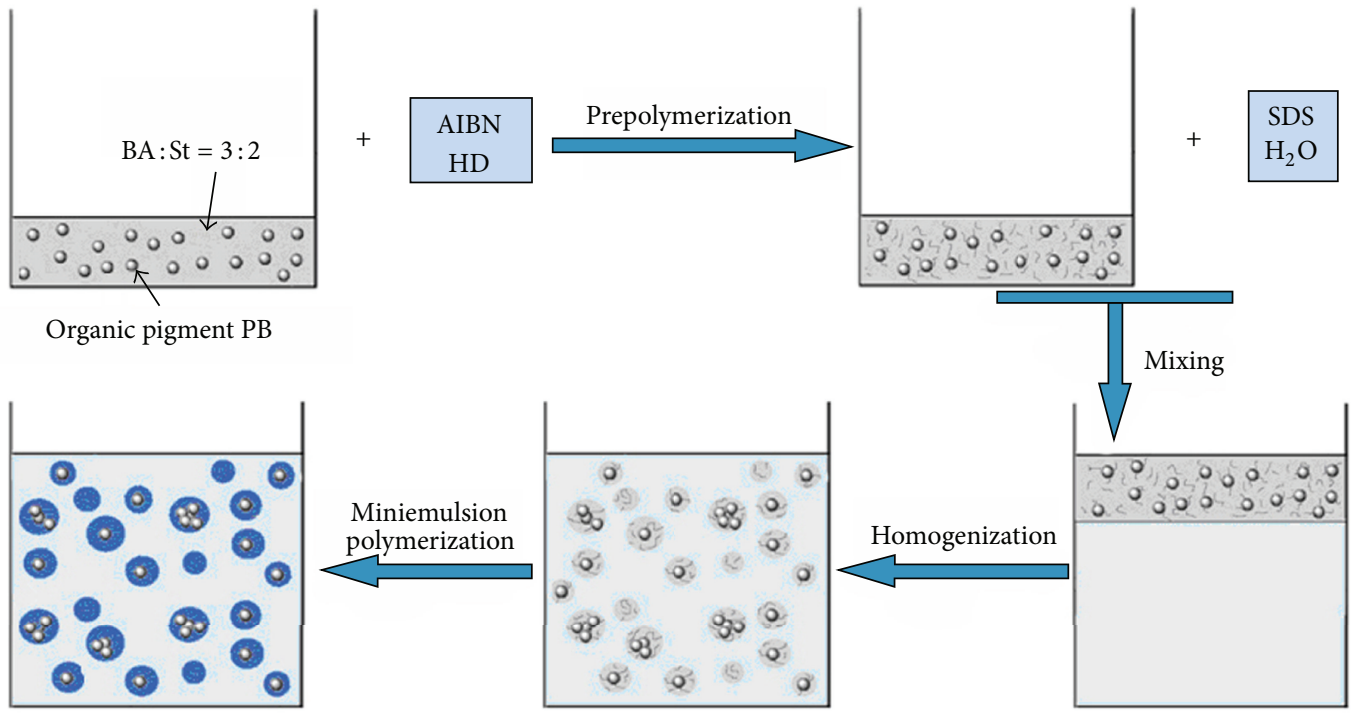

FIGURE 1: Schematic representation of the formation of self-adhesive polymer/organic pigment nanocomposites via miniemulsion polymerization.

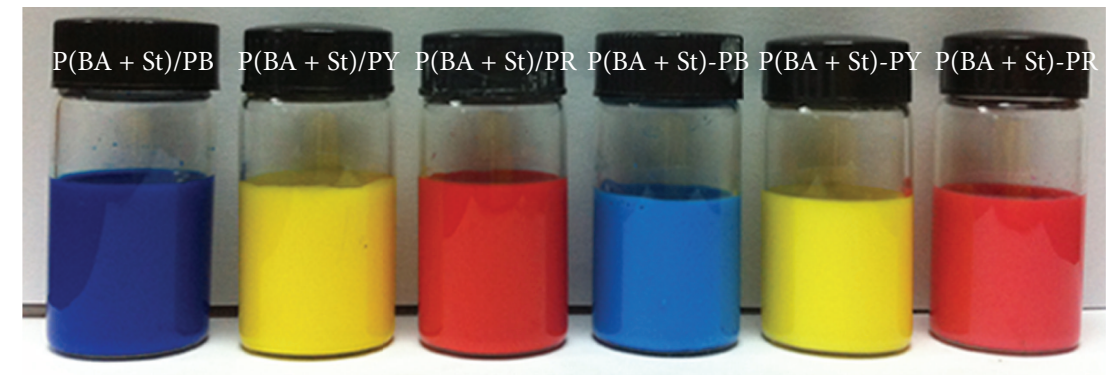

(a)

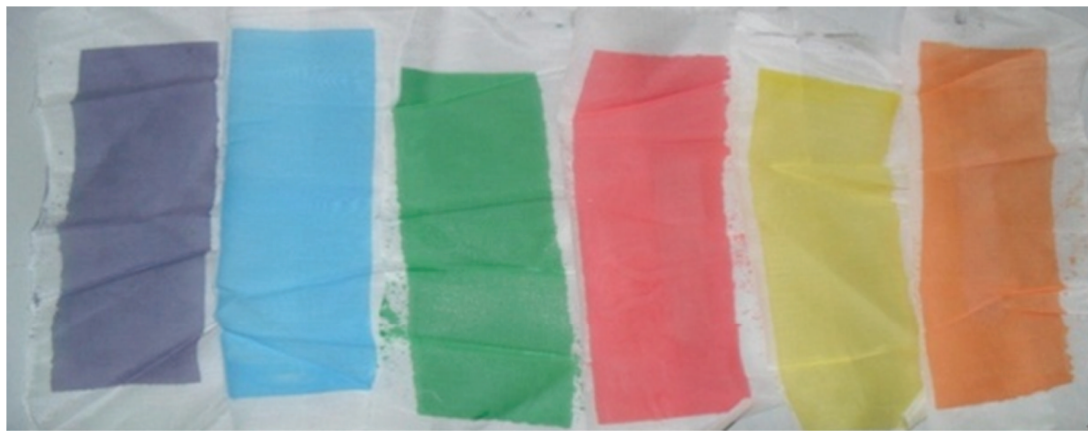

(b)

Figure 2: Photos of the polymer/pigment nanocomposite latexes and blended latexes with three primary color pigments (a) and the cotton fabrics pigment printed by nanocomposite latexes at different microcapsules ratio (b).

Both the rigid PSt particles with a regular spherical shape and the pigment particles PB with a rod-like structure could be observed in the blended PSt-PB latex (Figure 3(a)). In addition, some loose aggregates of pigment particles were also found in the continuous phase. In comparison, only micron-level aggregates were observed in the blended $\mathrm{P}(\mathrm{BA}+\mathrm{St})-\mathrm{PB}$ latex (Figure 3(b)). This can be reasonably attributed to the easy agglomeration of sticky $\mathrm{P}(\mathrm{BA}+\mathrm{St})$ particles and pigment particles, resulting from the low glass transition temperature of latex particles and the poor dispersion of pigments in the aqueous phase. 


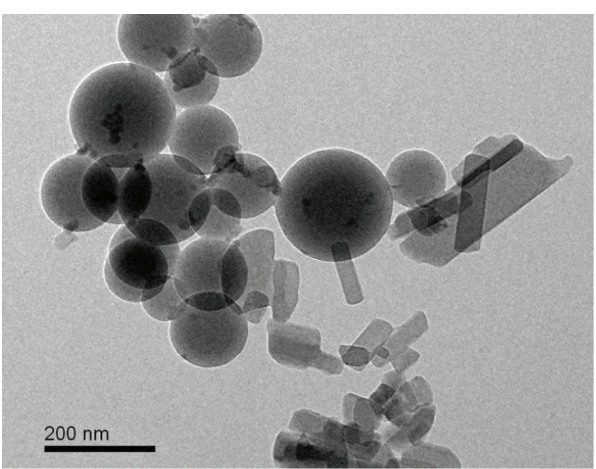

(a)

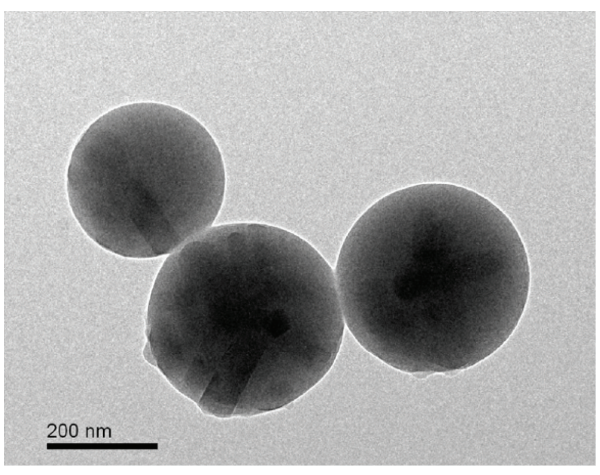

(c)

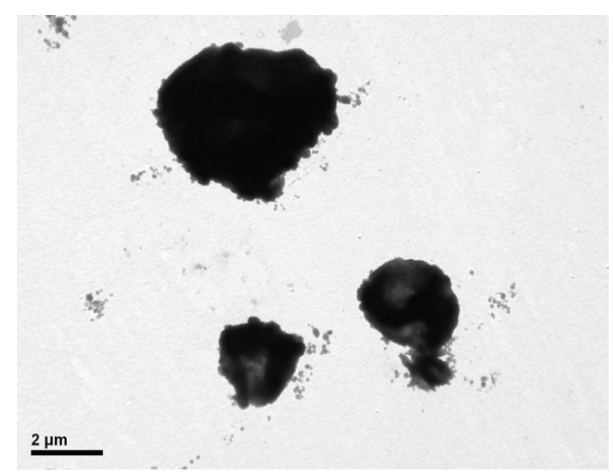

(b)

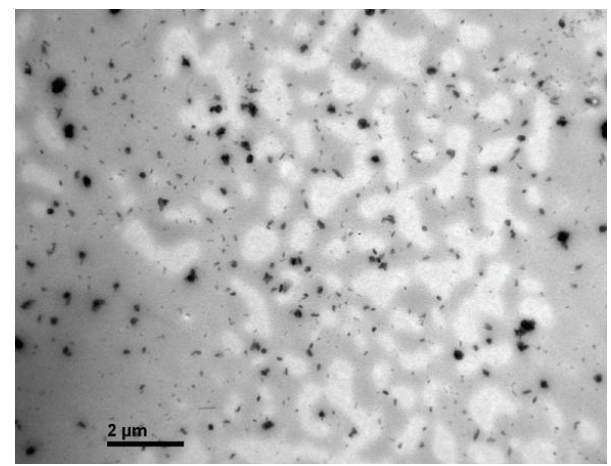

(d)

FIGURE 3: Typical TEM micrographs of organic pigment microcapsules PSt-PB (a), P(BA+St)-PB (b), PSt/PB (c), and P(BA+St)/PB (d).

As shown in Figure 3(c), the rod-like PB particles could be clearly seen in the spherical nanocomposites, indicating an effective encapsulation of pigment particles in the PSt particles via the miniemulsion technique. However, for the soft $\mathrm{P}$ $(\mathrm{BA}+\mathrm{St}) / \mathrm{PB}$ nanocomposites, the morphology of nanocomposites could not be well viewed by TEM (Figure 3(d)) due to the low glass transition temperature of the BA-St copolymers $\left(-8^{\circ} \mathrm{C}\right)$. It is believed that the light-colored shadows observed in the TEM image are the film of copolymers formed by the fusion of the soft shell during the preparation process of TEM sample. The aggregates consisted of several PB particles were uniformly dispersed in the entire field of vision. It was worth noting that the size of these pigment aggregates was less than the upper limit of organic microcapsules size (about $400 \mathrm{~nm}$ ). Moreover, all of these primary particles and aggregates were surrounded by the light-colored shadow. Therefore, we believe that the $\mathrm{P}(\mathrm{BA}+\mathrm{St}) / \mathrm{PB}$ nanocomposites have already formed, similar to the $\mathrm{PSt} / \mathrm{PB}$ nanocomposites shown in Figure $3(\mathrm{c})$. The shell of $\mathrm{P}(\mathrm{BA}+\mathrm{St})$ with a weight ratio of $\mathrm{BA}$ to St being $3: 2$ is soft enough to endow the $\mathrm{P}(\mathrm{BA}+\mathrm{St}) / \mathrm{PB}$ nanocomposites with an excellent self-adhesive characteristic. Therefore, no additional adhesives are required when the latexes of the $\mathrm{P}(\mathrm{BA}+\mathrm{St}) / \mathrm{PB}$ nanocomposites are applied to the pigment printing of fabrics.

3.2. Dispersion of Pigment Particles in Latex Films. To estimate the dispersion of pigment particles in adhesive films, the nanocomposite latex of $\mathrm{P}(\mathrm{BA}+\mathrm{St}) / \mathrm{PB}$ and the blended latex of
$\mathrm{P}(\mathrm{BA}+\mathrm{St})-\mathrm{PB}$ were dried in a PTFE mould, and the two thin films were observed by a $3 \mathrm{D}-\mathrm{POM}$ at a transmission mode.

For the blended latex film in Figure 4(a), the aggregates of pigment particles can be found in the whole film. The size of pigment aggregates is about $100 \mu \mathrm{m}$, much larger than that of the original particles in the blended latex. It implies that the pigment particles in the blended latex were further agglomerated during the process of film formation. In comparison, the large pigment aggregates are rarely seen in the film produced from the latex of the $\mathrm{P}(\mathrm{BA}+\mathrm{St}) / \mathrm{PB}$ nanocomposites, as shown in Figure 4(b). All of these reveal that the dispersion of pigment particles in the film made from the nanocomposites latex is more homogenous, and the large scale agglomeration of pigment particles could be suppressed by the encapsulation of organic pigments by an adhesive shell.

The dispersion of pigment particles on the film surface was further observed by FESEM, and the typical micrographs are shown in Figure 5.

The honeycomb structure, derived from the contact and deformation of the latex particles during the film formation $[13,14]$, can be observed on both of the film surfaces made from the nanocomposites latex and the blended latex. As shown in Figure 5(a), the whole surface of film made from the nanocomposites latex is clear, and some protuberances can be found at the centre of the hexagonal honeycombs, implying that the pigment particles had been embedded in the adhesive film. On the contrary, many irregular pigment aggregates were loosely adhered to the surface of film made 


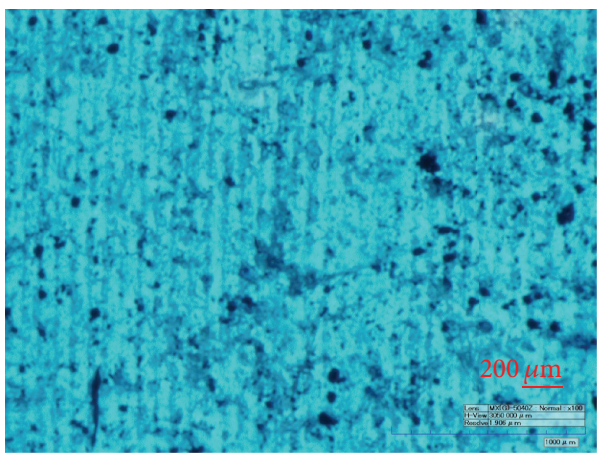

(a)

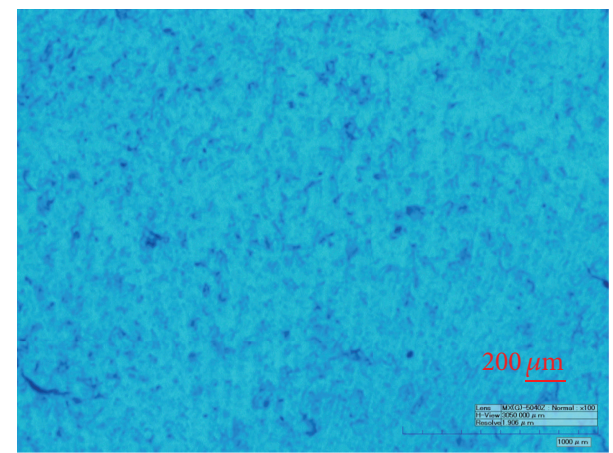

(b)

Figure 4: Typical 3D-POM images of the film made from the blended latex of $\mathrm{P}(\mathrm{BA}+\mathrm{St})-\mathrm{PB}$ (a) and the film made from the nanocomposite latex of the $\mathrm{P}(\mathrm{BA}+\mathrm{St}) / \mathrm{PB}(\mathrm{b})$ at a transmission mode.

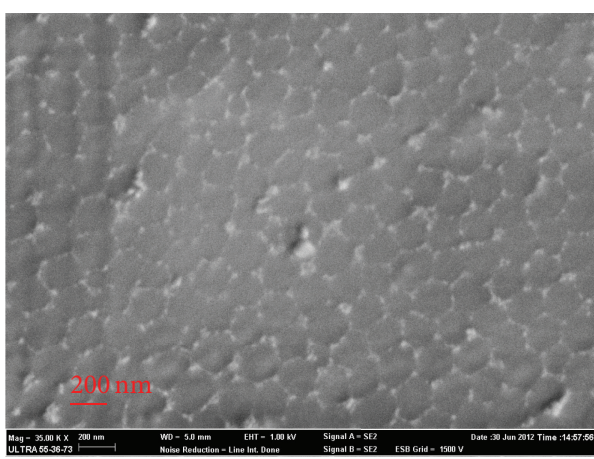

(a)

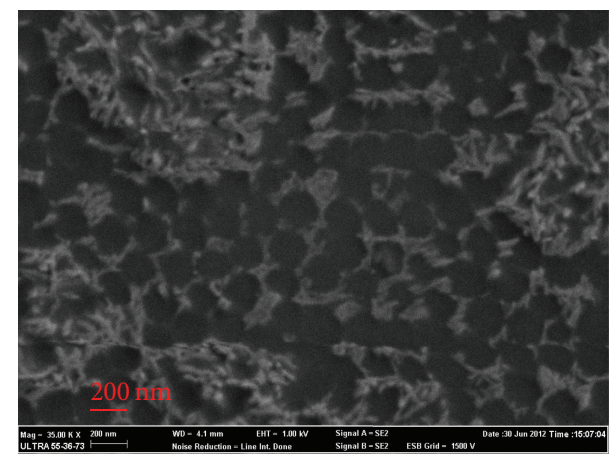

(b)

FIgure 5: Typical FESEM images of the film surfaces made from the latex of the P(BA+St)/PB nanocomposites (a) and the blended latex of $\mathrm{P}(\mathrm{BA}+\mathrm{St})-\mathrm{PB}(\mathrm{b})$.

from the blended latex, indicating a poor dispersion of pigment particles in this adhesive film, as well as a low adhesive strength between pigment particles and adhesive film. The differences in morphology would inevitably give birth to different printing qualities, such as color strength (K/S value), handle (stiffness), and rubbing fastness.

3.3. Color Effect of the Pigment Latex Films. It was indeed found that the printing qualities of cotton fabrics printed by the nanocomposites latex were very different from those printed by the blended latex.

As shown in Table 1, the K/S value of the fabric printed by the blended latex before soaping is 7.87 , which is higher than that printed by the nanocomposites latex, attributing to the enrichment of pigment particles on the surface of film printed by the blended latex (see Figure 5(b)). However, after soaping, the $K / S$ value of the fabric printed by the blended latex declined remarkably, while the value of the fabric printed by the nanocomposites latex remains nearly constant. These results clearly indicate a higher washing fastness of the latter, consistent with the result of rubbing fastness test. In Table 1, both the dry and the wet rubbing fastnesses of cotton fabric printed by the nanocomposites latex were better than those printed by the blended latex. On the other hand, the stiffness of the fabric printed by the nanocomposites latex is lower, leading to a softer handle.

All the abovementioned results reveal that the printing qualities of cotton fabric made from the nanocomposites latex were significantly better than those printed by the blended latex. Furthermore, these macroscopic performances can be well consistent with the microstructure shown in Figures 4 and 5 .

In addition, it was found that attributing to the uniform and stable dispersion of the pigment particles in the film made from the nanocomposites latex, the interference between different pigment particles in color effect can be effectively inhibited. And thus various colors of pigment coating can be accurately designed and facilely obtained simply by tuning the ration and amount of the nanocomposites with three primary color pigment particles, as shown in Figure 2(b).

\section{Conclusions}

Three primary color pigment/P(BA+St) nanocomposites with small sizes and better self-adhesion were successfully prepared by the miniemulsion technique. The presence of adhesive shell on pigment surface cannot only inhibit the 
TABLE 1: The printing qualities of cotton fabrics using the nanocomposites latex and blended latex as printing paste.

\begin{tabular}{|c|c|c|c|c|c|}
\hline \multirow{2}{*}{ Printing paste form } & \multicolumn{2}{|c|}{$K / S$ value } & \multirow{2}{*}{ Stiffness/cm } & \multicolumn{2}{|c|}{ Rubbing fastness/grade } \\
\hline & Before soaping & After soaping & & Dry & Wet \\
\hline Blended latex $\mathrm{P}(\mathrm{BA}+\mathrm{St})-\mathrm{PB}$ & 7.87 & 5.11 & 3.68 & $3-4$ & $2-3$ \\
\hline Nanocomposite latex $\mathrm{P}(\mathrm{BA}+\mathrm{St}) / \mathrm{PB}$ & 6.63 & 6.57 & 3.12 & 4 & $4-5$ \\
\hline
\end{tabular}

extensive agglomeration of pigment particles but can also synchronously improve the adhesion efficiency of the binder to pigments. Thus, the film made from the latex of the polymer/pigment nanocomposites shows a much better adhesion between pigment and adhesive and a better dispersion of pigment particles in the film than those of the film made from the blended latex film. Furthermore, these nanocomposites can be directly applied to the pigment printing of fabric without any additional adhesives. The dispersion, adhesiveness, and color effect of organic pigments in printed coating on fabric surface can be remarkably improved through the preencapsulation of pigments by an adhesive shell at the nanoscale. In addition, pigment coatings with various colors can be accurately designed and facilely obtained by tuning the ration and amount of the three primary pigment nanocomposites thanks to the minor interference of the encapsulated pigments in color effect.

\section{Conflict of Interests}

The authors declare no competing financial interest.

\section{Acknowledgments}

This work was financially supported by the National Natural Science Foundation of China (51003023 and 51273182) Zhejiang Provincial Natural Science Foundation of China (Y4100221), Training Foundation for the Excellent Young Talents by the Key Laboratory of Advanced Textile Materials and Manufacturing Technology, Ministry of Education (2010QN01), and Zhejiang Provincial Top Academic Discipline of Applied Chemistry and Eco-Dyeing \& Finishing Engineering (2012R10038).

\section{References}

[1] K. Hayashi, H. Morii, K. Iwasaki, S. Horie, N. Horiishi, and K. Ichimura, "Uniformed nano-downsizing of organic pigments through core-shell structuring," Journal of Materials Chemistry, vol. 17, no. 6, pp. 527-530, 2007.

[2] S. Fu, L. Ding, C. Xu, and C. Wang, "Properties of copper phthalocyanine blue encapsulated with a copolymer of styrene and maleic acid," Journal of Applied Polymer Science, vol. 117, no. 1, pp. 211-215, 2010.

[3] S. Fu, C. Xu, C. Du, A. Tian, and M. Zhang, "Encapsulation of C.I. Pigment blue 15:3 using a polymerizable dispersant via emulsion polymerization," Colloids and Surfaces A, vol. 384, no. 1-3, pp. 68-74, 2011.

[4] D. Nguyen, H. S. Zondanos, J. M. Farrugia, A. K. Serelis, C. H. Such, and B. S. Hawkett, "Pigment encapsulation by emulsion polymerization using macro-RAFT copolymers," Langmuir, vol. 24, no. 5, pp. 2140-2150, 2008.

[5] S. Lelu, C. Novat, C. Graillat, A. Guyot, and E. Bourgeat-Lami, "Encapsulation of an organic phthalocyanine blue pigment into polystyrene latex particles using a miniemulsion polymerization process," Polymer International, vol. 52, no. 4, pp. 542-547, 2003.

[6] N. Steiert and K. Landfester, "Encapsulation of organic pigment particles via miniemulsion polymerization," Macromolecular Materials and Engineering, vol. 292, no. 10-11, pp. 1111-1125, 2007.

[7] S. H. Fu and K. J. Fang, "Preparation of styrene-maleic acid copolymers and its application in encapsulated pigment red 122 dispersion," Journal of Applied Polymer Science, vol. 105, no. 2, pp. 317-321, 2007.

[8] J. Yang, T. J. Wang, H. He, F. Wei, and Y. Jin, "Particle size distribution and morphology of in situ suspension polymerized toner," Indutrial and Engineering Chemistry Research, vol. 42, no. 22, pp. 5568-5575, 2003.

[9] S. Kiatkamjornwong and P. Pomsanam, "Synthesis and characterization of styrenic-based polymerized toner and its composite for electrophotographic printing," Journal of Applied Polymer Science, vol. 89, no. 1, pp. 238-248, 2003.

[10] H. Widiyandari, F. Iskandar, N. Hagura, and K. Okuyama, "Preparation and characterization of nanopigmentpoly(styrene-co-w-butyl acrylate-co-methacrylic acid) composite particles by high speed homogenization-assisted suspension polymerization," Journal of Applied Polymer Science, vol. 108, no. 2, pp. 1288-1297, 2008.

[11] D. Qi, R. Zhang, L. Xu, Y. Yuan, and L. Lei, "Preparation and characterization of organic pigment phthalocyanine blue microcapsules by in-situ micro-suspension polymerization," Acta Polymerica Sinica, no. 2, pp. 145-150, 2011.

[12] K. Landfester and D. Crespy, "Miniemulsion polymerization," Materials Science and Technology, pp. 449-474, 2013.

[13] S. Zhang, S. Zhou, B. You, and L. Wu, "Fabrication of ordered porous polymer film via a one-step strategy and its formation mechanism," Macromolecules, vol. 42, no. 10, pp. 3591-3597, 2009.

[14] M. J. Patel, V. R. Gundabala, and A. F. Routh, "Modeling film formation of polymer-clay nanocomposite particles," Langmuir, vol. 26, no. 6, pp. 3962-3971, 2010. 

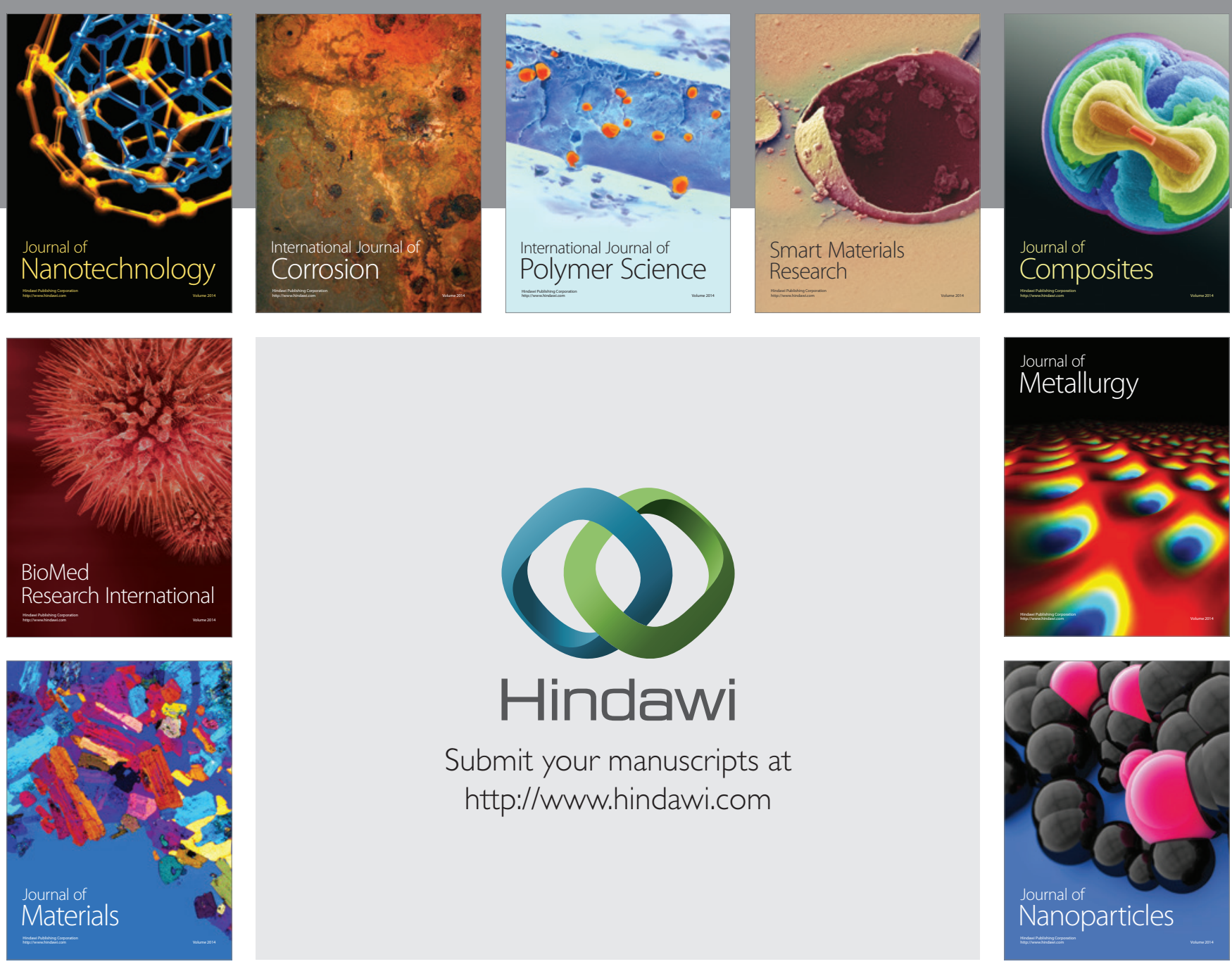

Submit your manuscripts at http://www.hindawi.com
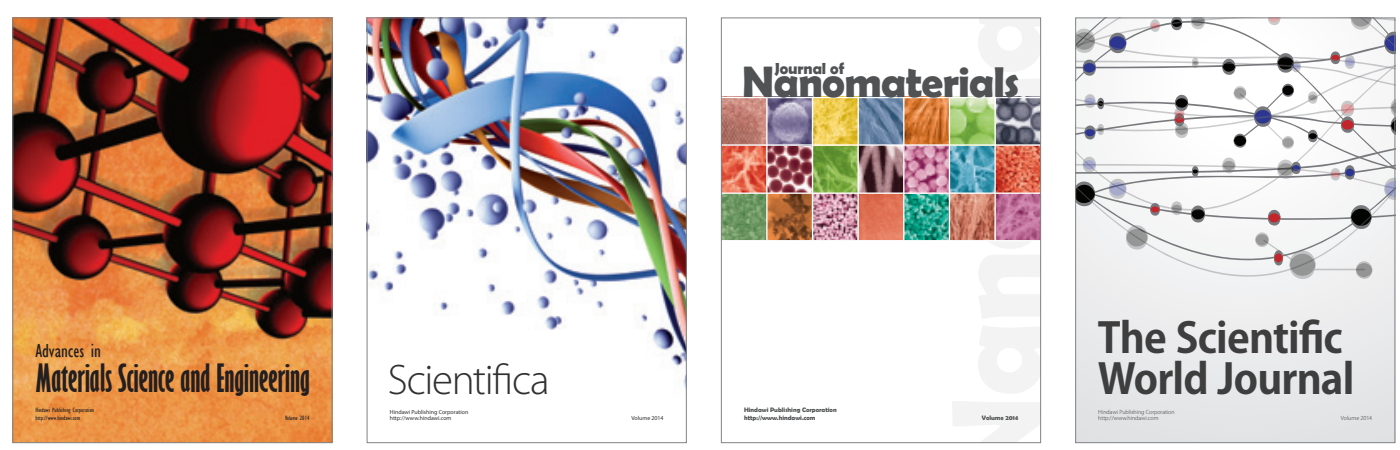

\section{The Scientific World Journal}
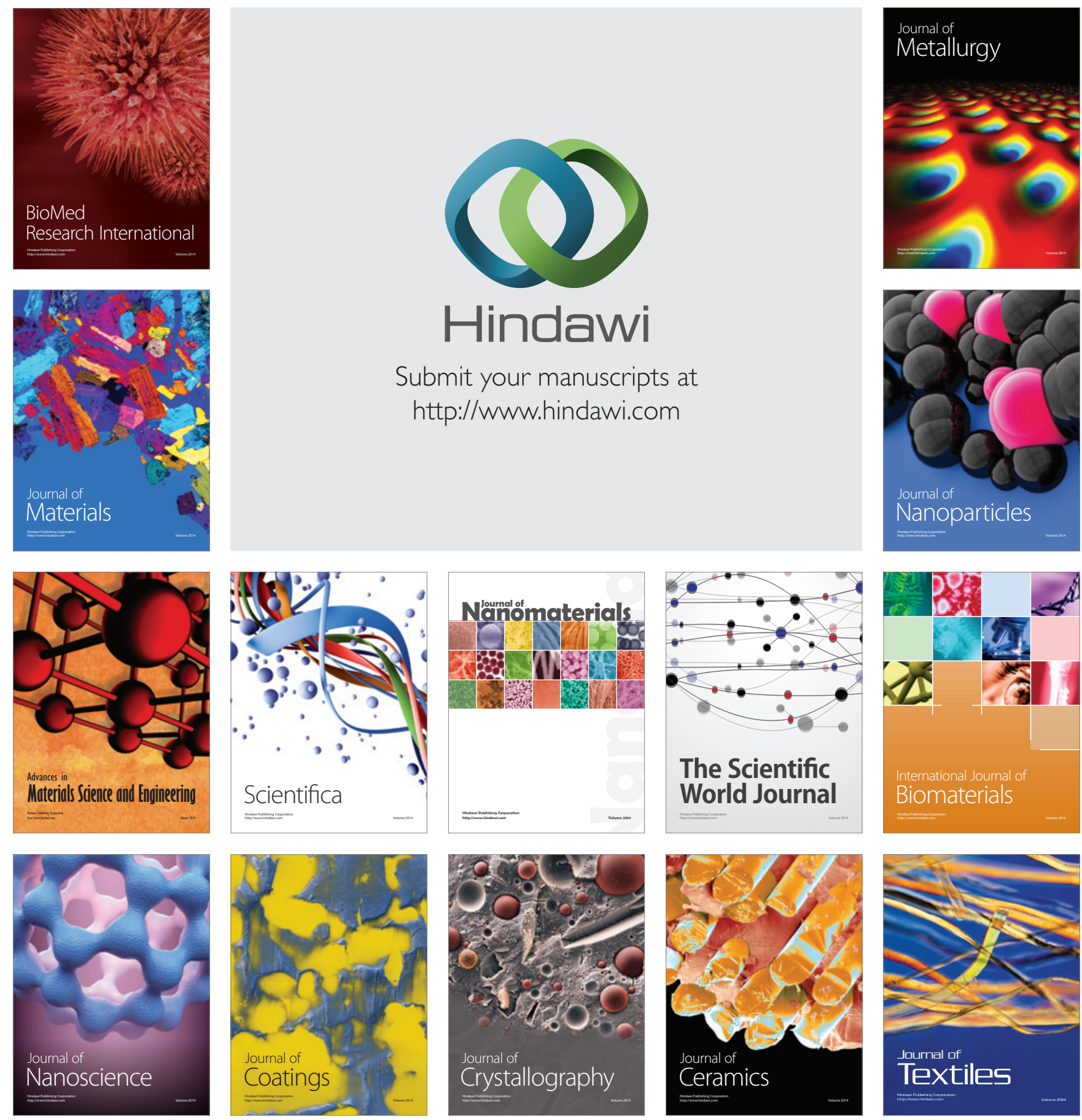